\title{
O Carmen Sacrum de Proba
}

\author{
Márcio Meirelles Gouvêa Júnior \\ Universidade Federal de Minas Gerais \\ Faculdade de Letras da Universidade de Coimbra. \\ gouvea.bh@terra.com.br \\ Il centone ha l'apparenza d'una catena d'oro, d'oro vergiliano. \\ Filippo Ermini
}

ABSTRACT: The Carmen Sacrum of Proba, a Roman aristocrat christianized in the fourth century, intends to evangelize, according to the concepts of orthodox soteriology, and is also based on metric juxtapositions of fragments from the works of Virgil. Here, we describe both aspects of this curious work.

KEYWORDS: Proba; Cento; Carmen Sacrum; apologetics; Athanasius of Alexandria.

\section{Introdução}

Atribui-se a uma certa Proba, aristocrata romana da segunda metade do século IV, a autoria do poema religioso de feições épicas, composto por 694 hexâmetros, em que se contam trechos das Escrituras cristãs. A obra, tradicionalmente conhecida como Cento Vergilianus Probae, foi elaborada segundo a técnica literária do centão, que constituía a intencional e evidente apropriação por um autor dos versos de outro, para a elaboração de nova narrativa em tudo diversa da original. Pela fragmentação e rearranjo dos versos de Virgílio, a matrona cristianizada, aparentemente com intuito de evangelização familiar, pôde recriar as histórias bíblicas, emprestando feições poéticas clássicas à nova crença religiosa que se afirmava no Império Romano, tornando-se, assim, a mais antiga poetisa cuja obra sobreviveu integralmente. ${ }^{1}$

Embora os manuscritos e as edições do texto tenham conferido à obra títulos como Versus Probae, Cento Virgilianus Probae, Cento Probae, Opus Probae Matronae ou Liber Cento Probae, ${ }^{2}$ o termo “centão" não se refere a um gênero literário específico, mas à técnica de composição poética. Por isso, parece ser mais adequada a terminologia oferecida pela própria poetisa que, no verso $9,{ }^{3}$ intitula seu texto de Carmen Sacrum.

\footnotetext{
${ }^{1}$ Cf. Meconi, D. V. The "Christian Cento" and the evangelization of Christian culture. Logos: a journal of catholic thought and culture. St. Paul: University St. Thomas, vol. VII, n. 4, p. 109-132, 2004.

${ }^{2}$ Cf. Ermini, F. Il "Centone di Proba" e la poesia centonaria latina. Roma: Ermanno Loescher \& $\mathrm{C}^{\circ}$, 1909.

${ }^{3}$ Cf. Proba, CS. 9: Nunc, deus omnipotens, sacrum, precor, accipe, carmen.
} 


\section{Autoria e data}

Apesar da autonomeação no verso 12 do poema, ${ }^{4}$ continua bastante difícil determinar com exatidão a identidade de Proba e, por conseguinte, a datação de sua obra. Isso porque ao menos duas mulheres com o mesmo nome, e pertencentes à mesma família, podem ser identificadas como a referida escritora.

A primeira das possíveis autoras, conhecida pelo nome de Faltônia Betítia Proba, foi mencionada duas vezes por Isidoro de Sevilha. ${ }^{5}$ Por esses testemunhos, do século VII, o centão virgiliano teria sido escrito pela esposa de Clódio Celsino Adelfo, prefeito de Roma em 351. Sua genealogia revela seu elevado status social, afinal, ela seria neta de Probo, cônsul em 310, filha de Petrônio Probino, cônsul em 322 e prefeito de 329 a $331 .^{6}$ Sendo assim, a presumível datação do poema circunscrever-se-ia às décadas de 350 e 370, considerando a data da morte de Faltônia Betítia o ano de 372. Nesse sentido, duas poderiam ser as motivações da centonista: ou a singela vontade de converter o marido e os netos à fé cristã, ou o Decreto Imperial de Juliano, de 362.

A primeira hipótese causal do poema, ${ }^{7}$ de certo modo simplista, foi adotada pelos primeiros editores do seu texto. Considerando a prática emulatória do processo educacional da Antiguidade, pela qual os estudantes e aspirantes à carreira literária esforçavam-se por imitar os autores reputados canônicos; ${ }^{8}$ e considerando a conversão de crentes pertencentes a uma camada culta da sociedade romana, que julgavam rústico e pouco clássico o estilo da Bíblia e dos Evangelhos escritos na koiné, ${ }^{9}$ a poetisa teria buscado fornecer à educação religiosa de seu marido e de seus netos ${ }^{10}$ uma obra capaz de transmitir as mensagens religiosas em um texto de elevada consideração literária, já que elaborado a partir dos versos do mais celebrado autor latino. Nesse sentido, a

\footnotetext{
${ }^{4}$ Cf. Proba, CS. 12: Arcana ut possim uatis Proba cuncta referre.

5 Cf. Isid. Etim. 39.26: Denique Proba, uxor Adelphi, centonem ex Vergilio de fabrica mundi et Euangeliis plenissime expressit, materia conposita secundum uersus, et uersibus secundum materiam concinnatis. E cf. Isid. De Civ. 22: Proba, uxor Adelphii proconsulis, femina inter uiros ecclesiasticos posita.

${ }^{6}$ Cf. Sivan, H. Ancian women, the "Cento of Proba", and aristocratic conversion in the fourth century. Vigiliae Christianae. Leiden, vol. XLVII, p. 141, 1993.

7 Cf. Arbea, A. El "Carmen Sacrum" de Faltonia Betitia Proba, la primera poetisa cristiana. Cyberhumanitatis. Santiago: Pontificia Universidad Católica de Chile, n. XI, p. 5, 1999 (disponível em < http://www2.cyberhumanitatis.uchile.cl/11/arbea.html> acesso em 12 abr. 10).

${ }^{8}$ Cf. August. Conf. 1.17: Sed figmentorum poeticorum uestigia errantes sequi cogebamur, et tale aliquid dicere solutis uerbis quale poeta dixisset uersibus.

${ }^{9}$ Cf. August. Conf. 3.5: Cum attendi ad illam scripturam, sed uisa est mihi indigna quam tullianae dignitati compararem.

${ }^{10}$ Cf. Proba, CS, 693-694: O dulcis coniunx, et si pietate meremur, hac casti maneant in religione nepotes. 
indicação da Epistola 53, de Jerônimo a Paulino de Nola, ${ }^{11}$ datada de 394, na qual o prelado criticou o uso das obras clássicas para a interpretação das Escrituras, faz supor que a garrula anus, ou a velha faladeira, fosse Faltônia Betítia.

A segunda hipótese de motivação dessa Proba refere-se à proibição do imperador apóstata Juliano ao uso dos textos clássicos na educação dos cristãos. ${ }^{12} \mathrm{O}$ argumento de Juliano, que tentara restaurar o paganismo no Império, baseava-se na idéia de que qualquer um que discordasse da teologia de Homero, de Hesíodo e de Virgílio encontrava-se impossibilitado de ensinar a partir de suas obras. ${ }^{13}$ Por esse motivo, e sem textos que o auxiliassem na tarefa de propagação de uma fé tão estreitamente ligada ao livro e à transmissão dos textos, Proba teria utilizado os versos da Eneida, das Bucólicas e das Geórgicas para descrever a queda bíblica do homem e sua salvação evangélica, sem afrontar a proibição imperial, mas ainda assim por meio dos textos clássicos.

Entretanto, uma segunda possibilidade de autoria conduz a atribuição do Carmen Sacrum a outra poetisa, chamada Anícia Faltônia Proba, amiga de Agostinho de Hipona e de João Crisóstomo. ${ }^{14}$ De fato, esta Proba pertenceria à mesma família de Faltônia Betítia, sendo sua neta e mulher de Sexto Petrônio Probo, procônsul da África em 358 e cônsul em 371. Essa hipótese, fundada em evidências do poema anônimo Carmen contra paganos, adianta o terminus a quo da produção do centão para a década de 380. ${ }^{15}$ Além disso, a morte do Sexto Petrônio antes de 410 oferece o terminus ante quem da elaboração do poema, em razão da alusão ao esposo presente nos versos de encerramento da obra.

De qualquer modo, mesmo sem a precisa identidade da poetisa e da data do centão, podem-se depreender do texto, com certa facilidade, mas com todo o risco daí proveniente, algumas indicações sobre a formação sóciointelectual da escritora. Presume-se, pelos versos 1-8 do proêmio, que ela também tenha escrito ao menos uma obra anterior ao cento vergilianus, de temática não bíblica. ${ }^{16}$ Os versos $C S$. $48-49^{17}$

\footnotetext{
${ }^{11}$ Cf. Hier. Ep. 53.7: Hanc garrula anus, hanc delirus senex, hanc soloecista uerbosus, hanc uniuersi praesumunt, lacerant, docent, antequam discant.

${ }_{12}$ Cf. Marrou, H.-I. História da educação na Antiguidade. São Paulo: EPU, 1973, p. 462.

${ }^{13}$ Cf. Meconi, op. cit., p. 115.

${ }^{14}$ A ela foram endereçadas as Epistulae 130 e 131, de Agostinho, e a Epistula 169, de João Crisóstomo.

${ }^{15}$ Cf. Shanzer, D. The anonymous "Carmen contra paganos" and the date and identity of the centonist Proba. Revue des études augustiniennes. Paris, vol. XXXII, p. 247, 1986.

${ }^{16}$ Cf. Proba, CS. 1-8: Iam dudum temerasse duces pia foedera pacis,/ regnandi miseros tenuit quos dira cupido,/ diuersasque neces, regum crudelia bella/ cognatasque acies, pollutos caede parentum/ insignis
} 
alicerçam tal hipótese, permitindo a inferência de que as crudelia bella cognatasque acies se referissem às disputas entre Constantino e Maxêncio pelo mando imperial, ${ }^{18}$ na batalha da Ponte Mílvia em 312. Presume-se também que ela fosse conhecedora tanto da Bíblia quanto dos textos clássicos, ${ }^{19}$ quanto mais que a técnica da confecção dos centões pressupunha a precisa e bem gravada lembrança dos trechos compilados, como descreve Ausônio em seu Liber $18 .^{20}$ Presume-se ainda que a conversão da poetisa não fosse de todo modo antiga, como fazem crer os versos $21-22,{ }^{21}$ pois seu batismo teria se dado já em um momento de consciência adulta. Presume-se, finalmente, que ela fosse realmente da aristocracia romana cristianizada e que sua obra tivesse, de alguma maneira, função apologética.

\section{Estrutura da obra}

Composto sob das regras centonistas clássicas, o poema de Proba foi feito a partir da fragmentação e da justaposição métrica dos versos de Virgílio. ${ }^{22}$ Desse modo, preservou-se a cadência heróica dos hexâmetros originais, de tal maneira que algo do ethos grandioso do gênero épico da Antiguidade pôde ser transmitido à nova obra.

De fato, a técnica literária do centão era de antigo conhecimento ao tempo de Proba, remontando ao início da literatura clássica. ${ }^{23}$ Restringindo, contudo, a reflexão ao âmbito da literatura latina, já no século II havia produções centonistas, como a tragédia Medea, de Hosídio Geta. Entretanto, o uso dado à técnica pelos autores pagãos tinha por objetivo mais "fazer rir do que louvar", como Ausônio descreveu e exemplificou no Cento Nupcialis, que acompanha o Liber 18. Contudo, em uma prática que se tornou majoritária a partir do século IV, os centões perderam sua feição jocosa

clipeos nullosque ex hoste tropea,/ sanguine conspersos tulerat quos fama triumphos, innumeris totiens uiduatas ciuibus urbes,/ confiteor, scripsi.

${ }^{17}$ Cf. Proba, CS. 48-49: Semper equos atque arma uirum pugnasque canebam/ et studio incassum uolui exercere laborem.

${ }^{18}$ Cf. Ermini, op. cit., p 13.

${ }^{19}$ Cf. Proba, Faltonia B. Centones Probae Falconiae de utriusque testamenti hystoriis ex carminibus Virgilii selecti cum annotatione locorum, ex quibus desumpti sunt. Oppenheymium: 1517 (disponível em $<$ http://daten.digitale-sammlungen.de/ db/bsb00002244/images> acesso em 12 abr. 10).

${ }^{20}$ Cf. Aus. Epist 13: Centonem uocant, qui primi hac concinnatione luserunt. Solae memoriae negotium sparsa colligere et integrare lacerata, quod ridere magis quam laudare possis.

${ }^{21}$ Cf. Proba, CS. 21-22: Quae sitiens hausi sanctae libamina lucis/ hinc canere incipiam.

${ }^{22}$ Para as alterações nos versos de Virgílio efetuadas por Proba, cf. Ermini, op. cit., p. 101-102.

${ }^{23}$ Cf. Dominguez, O. P. Historia del Centón griego. Cuadernos de filología clásica. Estudios griegos e indoeuropeos. Madrid: Universidad Complutense, 2009, p. 217-232. 


\section{nuntius antiquus}

inicial e adquiram aspectos apologéticos, em consonância com a prática da igreja primitiva de utilizar o melhor da cultura não cristã para falar de Cristo. ${ }^{24}$

Por isso, como poema de algum modo épico, o Carmen Sacrum estruturou-se segundo o cânone, apresentando bem delineadas suas propositio, invocatio (v. 1-55) e enarratio (v. 56-694). Mas a utilização da técnica centonista propriamente dita iniciouse apenas a partir do verso 29 quando, após sua recusatio em prosseguir cantando os temas não religiosos, a poetisa começou a sequência poética das citações formadoras do centão. Na verdade, os propósitos da centonista, escritos ainda nos trechos autorais, encontram-se bem delineados na palinódia do verso $18:^{25}$ "Que eu narre os dons de Cristo, como se Virgílio os houvesse cantado”. Ela, então, tendo invocado o auxílio de Deus, propôs retornar sua narrativa à origem das coisas e aos feitos dos homens anteriores a de Moisés, afirmando, no verso $39,{ }^{26}$ que "feliz é aquele que pode conhecer as causas de tudo".

Tem início a descrição da formação divina do universo, em uma minuciosa reescrita latina do Gênesis bíblico. $\mathrm{O}$ momento anterior à Criação foi narrado por meio da apropriação dos versos 724-725 do Canto VI da Eneida, quando Eneias, em visita ao Orco, fora iniciado na teologia clássica por Anquises. ${ }^{27}$ Seguiram-se os dias da Criação (v. 56-114), descritos pelo rearranjo dos versos das Geórgicas, cuja temática campestre permitiu uma melhor figuração dos fenômenos da natureza (v. 58-59, 66, 68-69, 71-81, 88, 90, 92-94, 95-97, 102-103, 105-106, 108). Depois, narrou-se a criação do homem, a partir do feliz barro, ${ }^{28}$ e da mulher, a partir da costela do esposo, ${ }^{29}$ com a indicação da vida sem fadigas, velhice ou morte havida no Jardim do Éden (v. 115-146). Era o anúncio do estado paradisíaco da existência humana antes do pecado e da queda do homem. ${ }^{30}$ Contou-se ainda a colheita do fruto da árvore proibida (v. 147-169), quando a morte foi anunciada como a punição pela desobediência. ${ }^{31}$

\footnotetext{
${ }^{24}$ Cf. Meconi, op. cit., p. 110.

${ }^{25}$ Cf. Proba, CS. 18: Vergilium cecinisse loquar pia munera Christi.

${ }^{26}$ Cf. Proba, CS. 39: Felix qui potuit rerum cognoscere causas.

${ }^{27}$ Cf. Proba, CS. 56-57: Principio caelum ac terras camposque liquentes/lucentemque globum lunae.

${ }^{28}$ Cf. Proba, CS. 115-116: Felicemque trahit limum, fingit premendo/ pingue solum.

${ }^{29} \mathrm{Cf}$. Proba, CS. 128: Harum unam iuueni laterum compagibus artis/ eripuit.

${ }^{30}$ Cf. Proba, CS. 142-145: His ego nec metas rerum nec tempora pono:/ imperium sine fine dedi, multosque per annos/ rastros patietur humus, non uinea falcem./ At genus immortale manet, nec tarda senectus/ debilitat uires animi mutatque uigorem.

${ }^{31}$ Cf. Proba, CS. 151-152: Hac quicumque sacros decerpserit arbore fetus, morte luet merita: nec me sententia uertit.
} 


\section{nuntius antiquus}

Como no texto bíblico, a narrativa prosseguiu com a descrição da tentação e da queda do homem (v. 170-209). São curiosos os argumentos da serpente para o convencimento de Eva: a afirmação de que a proibição divina seria mera superstição ${ }^{32}$ e uma obscura indagação quanto ao proveito da vida eterna. ${ }^{33}$ Então, como no passo bíblico, a mulher, seduzida pela serpente, provou do fruto e o deu ao marido, descobrindo ambos a nudez, a vergonha e a culpa. Decorreram a expulsão do paraíso, a punição da serpente, do homem e da mulher e a decretação da morte, das dores e do trabalho, em evidente afirmação da nova condição mortal do ser humano, que teve, pela morte, a corrupção inserida na carne (v. 210-277). ${ }^{34}$

Na sequência, foi feita a descrição da concepção dos gêmeos Caim e Abel e do primeiro fratricídio (v. 278-306). Houve ainda uma breve indicação do dilúvio, da sobrevivência de Noé (v. 313-316) e uma versão bastante resumida do Êxodo dos hebreus do Egito (v. 319-332), encerrando-se, assim, a narrativa veterotestamentária.

Os seguintes versos passaram a narrar o Novo Testamento. Uma nova propositio (v. 333-345) anuncia o tema do canto: a vida e os feitos de Cristo. ${ }^{35}$ A partir daí, foram reportados o seu nascimento, o aparecimento da estrela de Belém, a chegada dos reis magos, o massacre dos inocentes e uma delicada manjedoura, retirada inteiramente da Bucólica $4^{36}$ (v. 346-383). Foram contados ainda os eventos do batismo (v. 384-428), a tentação no deserto (v. 384-455), a escolha dos discípulos e o sermão da montanha, em cujo episódio há tanto a descrição física do inferno ${ }^{37}$ (v. 456-504) quanto a admoestação a uma vida reta segundo os preceitos da justiça e o culto a um só Deus. ${ }^{38}$ Seguiu-se o episódio do acalmar do mar e do passeio por sobre as águas, em uma cena de tempestade bastante próxima dos recorrentes topoi épicos clássicos (v. 456-561). Depois, Proba descreveu a chegada de Cristo a Jerusalém sobre um asno e a expulsão dos vendilhões do Templo (v. 562-579), a última ceia e a predição de Sua morte (v.

\footnotetext{
${ }^{32}$ Cf. Proba, CS. 189-190: Quid prohibet causas penitus temptare latentes? Vana superstitio.

${ }^{33}$ Cf. Proba, CS. 191-192: Quo uitam dedit aeternam? Cur mortis adempta est/ condicio?

${ }^{34}$ Cf. Proba, CS. 261-262: Insuper his subeunt morbi tristique senectus/ et labor et durae rapit inclementia mortis.

${ }^{35}$ Cf. Proba, CS. 333-335: Nunc ad te et tua magna, pater, consulta reuertor. Maius opus moueo: uatum praedicta priorum agredior.

${ }^{36}$ Cf. Proba, CS. 377-379: Hic tibi prima ,puer, fundent cunabula flores,/ mixtaque ridenti passim cum baccare tellus/ olli paulatim colocasia fundet acantho.

${ }^{37}$ Cf. Proba, CS. 483-484: Turbidus hic caeno uastaque uoragine gurges/ aestuat atque imo barathri eructat harenam.

${ }^{38}$ Cf. Proba, CS. 469-473: Discite iustitiam moniti, succurrite fessis/ pro se quisque, uiri, quae cuique est copia, laetil communemque uocate deum. Meliora sequamur quoque uocar uertamus iter. Via prima salutis/ intemerata fides et mens sibi conscia recti.
} 
580-599), o julgamento e a paixão (v. 600-614), a crucificação (v. 615-649) e a ressurreição ao terceiro dia (v. 650-676). ${ }^{39}$ Finalmente, encerrando o poema, a autora fez seu pedido para que os amigos celebrassem os rituais sagrados e o esposo e os netos permanecessem na nova fé (v. 677-694).

Porém, nesse incansável encadeamento dos trechos virgilianos, a poetisa foi obrigada a alterar não apenas alguns dos versos, como já mencionado, mas também alguns sentidos dos trechos originais, para que a nova acepção cristã pudesse ser alcançada. Por exemplo, a relativa homofonia entre os nomes permitiu que o mítico poeta grego Museu, citado por Virgílio no verso 667, do Canto VI da Eneida, ${ }^{40}$ se tornasse o Moisés hebraico, no verso 36 do Carmen Sacrum. ${ }^{41}$ Do mesmo modo, os epítetos de Júpiter se adequaram às invocações cristãs a Deus Pai, como Pater omnipotens (Eneida X, 100 e CS, 64), hominum rerumque repertor (Eneida XII, 829 e $C S, 210)$, e os apelidos heróicos de Eneias serviram a Cristo, como diuinae stirpis origo (Eneida XII, 166 e CS, 347).

Mas não apenas o sentido dos versos virgilianos foi alterado na composição poética de Proba. Também a narrativa bíblica teve, algumas vezes, de ser mudada, para se expressar por meio do limitado estoque de fragmentos originais. Por exemplo, a passagem bíblica do Dilúvio foi readequada (v. 307-309), pois o assassinato de Abel passou a ser a motivação da ira divina, em claro desacordo com a narrativa do Gênesis $(G n .6,7)$, que remonta a destruição da vida na terra às impiedades e à maldade que se haviam instalado nos corações dos homens.

Já em contexto neotestamentário, quando as diferenças entre a obra da centonista e a narrativa os Evangelhos parecem mais se acentuar, o episódio da Fuga para o Egito (Mt. 2, 13) também foi remodelado. Se, no Evangelho de Mateus, José recebeu a notícia do massacre dos inocentes, no Carmen Sacrum, por seu turno, quem soube do perigo foi Maria, estranhamente dotada de capacidade premonitória (prescia uenturi), como a Sibila do canto VI da Eneida, a quem se referia o verso no original. Além disso, a viagem para o Egito foi omitida, e o refúgio de Jesus contra a ira de Herodes se deu no estábulo onde se encontrava a manjedoura (v. 372-374).

\footnotetext{
${ }^{39}$ Cf. Proba, CS. 649-650: Tertia lux gelidam caelo dimouerat umbram: iamque pedem referens superas ueniebat ad auras.

${ }^{40} \mathrm{Cf}$. Virg. Aen. VI, 667: Musaeum ante omnes, medium nam plurima turba.

${ }^{41}$ Cf. Proba, CS. 36: Musaeum ante omnes uestrum cecinisse por orbem.
} 


\section{nuntius antiquus}

Outros episódios adequados foram o do apaziguamento do mar (Mt. 8, 23-26; Mc. 4, 35-41; e Lc. 8, 22-25) e o do caminhar sobre as águas (Mt. 14, 22-33, Mc. 6, 4552, e Jo 6, 16-21). Descritos em trechos apartados dos Evangelhos, esses eventos foram reunidos em um só momento narrativo (v. 456-561). Do mesmo modo, na descrição da Última Ceia (Mt. 26,26-29; Mc. 14, 17-25; Lc. 22, 14-38) o cenáculo desapareceu e a refeição foi descrita sob contexto clássico, com os comensais recostados na relva, como os marinheiros de Eneias no Canto I da Eneida.

Finalmente, a descrição probiana da ressurreição (v. 644-686) também alterou o sentido dos textos evangélicos, porquanto condensa os acontecimentos posteriores à ressurreição. Na narrativa centonista, não foi o anjo quem anunciou que o sepulcro se encontrava vazio (Mt. 28; Mc. 16; Lc. 24; Jo 20), mas o próprio Cristo, descrito a deixar a tumba em grande esplendor, a anunciar os prêmios pela piedade.

De fato, todas essas apropriações dos versos virgilanos não se deram de modo ingênuo, mas para transformar o Cristo das Escrituras em uma forma de herói épico, ainda moldado segundo as concepções da Antiguidade. Por isso, o Cristo do centão é expressamente chamado de heros, ${ }^{42}$ como Eneias, no verso 672 do Canto VI da Eneida. Além disso, a crucificação reconstruída por Proba nos versos 615-649 afasta-se sobremaneira do caráter sacrificial existente nos Evangelhos (Lc. 23, 34), pois o Cristo recriado, em vez de perdoar a seus perseguidores, torna-se o vingador que anuncia a seus adversários a punição vindoura. ${ }^{43}$ Do mesmo modo, a manifestação divina no batismo (Mt. 3, 17; Mc. 1, 11; Lc. 3, 22), em que o Deus bíblico disse "Tu és meu Filho bem amado e em ti ponho minha afeição", foi adaptada, no verso 403, segundo fala do velho Anquises a seu cioso filho presente no verso 664, do Canto I, da Eneida. ${ }^{44}$ Além do próprio conteúdo intrínseco ao verso, manteve-se assim o sentido original do texto latino, uma vez que a pietas do herói virgiliano transmitiu-se ao herói de Proba, aproximando-o dos valores romanos de dever filial e de reverência, ainda existentes mesmo na transição do paganismo.

\section{Cristo como novo Adão: Proba evangelizadora}

\footnotetext{
${ }^{42}$ Cf. Proba, CS. 518, e cf. Virg. Aen. VI, 672: Atque huic responsum paucis ita reddidit heros.

${ }^{43}$ Cf. Proba, CS. 621-623: "Quo vincula nectitis"? inquit/ "tantane uos generis tenuit fiducia uestri?/ Post mihi non simili poena commissa luetis".

${ }^{44}$ Cf. Proba, CS. 403: Nate, meae uires, mea magna potentia solus. 
Juntamente com os elementos históricos e estruturais do texto de Proba, os aspectos teológicos da obra apresentam-se como fator indispensável para compreensão global do Carmen Sacrum. É clara a divisão do centão em duas grandes porções narrativas, anunciadas pelas duas propositiones - uma, do Antigo, e outra, do Novo Testamento. É clara também a opção da poetisa por centrar as atenções nas figuras de Adão e de Cristo, ou, em outras palavras, em dois momentos fulcrais da crença cristã: a queda do homem e sua salvação. Todavia, o argumento do paralelo entre Adão e Cristo não era novidade no processo de conversão ao cristianismo nos primeiros séculos de propagação da fé, uma vez que já havia sido utilizado pelo próprio apóstolo S. Paulo, no sentido de demonstrar que o Cristo resgatara o homem do pecado inserido na carne por Adão (1 Cor. 15, 20-21; Rm. 5, 17-19).

Desse modo, e para aprofundar a reflexão acerca da analogia - estabelecida por Paulo e seguida por Proba - entre Adão e Cristo, é válida a apropriação da argumentação elaborada por Atanásio sobre o tema, guardadas, contudo, as devidas ressalvas. De fato, o contexto histórico e teológico em que se originou o pensamento do bispo de Alexandria diferia em muito do contexto latino de Proba. Afinal, a argumentação apologética cristológica de que participou Atanásio não foi motivada pela conversão dos pagãos ao cristianismo - como no caso de Proba -, mas sim pela definição da ortodoxia acerca das interpretações da natureza do Filho em relação ao Pai. Além disso, o propósito de convencimento de Atanásio dava-se dentro de um cristianismo já instalado nas estruturas de poder dominante, com o intuito maior de combater as posições teológicas do arianismo, consideradas heréticas. Proba, por sua vez, encontrava-se inserida no contexto de um cristianismo não completamente estabelecido, ainda fortemente influenciado pela filosofia e pela cultura helenística. Por isso, seu esforço parece ter sido o de demonstrar a possibilidade de harmonização entre o homem romano - patriota, culto e admirador do patrimônio de sua nação - e o cristão - considerado ainda inculto e rústico. ${ }^{45}$ Entretanto, a argumentação de Atanásio permite ao leitor moderno acesso aos elementos da analogia estabelecida por Proba, sem que as particularidades teológicas do bispo alexandrino comprometam, todavia, a proposta de elucidação do Carmen Sacrum.

\footnotetext{
${ }^{45}$ Cf. Stevenson, J. Women Latin poets. Language, gender and authority. Oxford: University Press, 2005, p. $65-71$.
} 
Pela argumentação de Atanásio, como um dos elementos fundamentais da fé cristã primitiva, a imortalidade do corpo e da alma configurava a promessa central da nova crença, como se pode ver no Credo de Niceia: "Creio na ressurreição da carne e na vida eterna." ${ }^{46}$ Entretanto, para que essa argumentação se tornasse de fato convincente, foi necessário ao Bispo de Alexandria retomar, em seu percurso apologético, a narrativa bíblica adâmica. Isso porque, segundo sua compreensão teológica, a primeira decisão divina teria sido a de instalar o homem recém-criado no jardim do paraíso onde, em uma existência beatífica e enquanto a piedade e a obediência aos mandamentos divinos fossem preservadas, não haveria dor, trabalhos ou morte. ${ }^{47}$ Entretanto, pelo livrearbítrio, a desobediência levou o homem a pecar, e ele se tornou sujeito à corrupção e à morte, afastando-se, portanto, da natureza eterna havida no ato da Criação. ${ }^{48}$ Sob o pecado, a humanidade inteira caminhava para a perda, com o previsível desaparecimento do homem e a ruína integral da obra divina. No entanto, a misericórdia de Deus não permitiria tal fim para a Criação, embora a coerência teológica em relação à perfeição divina também não permitisse que a pena imposta por Deus ao homem fosse relevada, sob o argumento de que Ele jamais mentiria. ${ }^{49}$ Por isso, convinha-Lhe que o Verbo, ou Seu Filho gerado, encarnasse, porque só assim, na carne, o pecado de Adão seria redimido e o homem poderia regressar ao estado de perfeição inicial de Deus. Afinal, para vencer a corrupção que se instalara na carne, a morte deveria ser vencida, e isso só poderia se dar por meio da ressurreição, quando o Cristo encarnado derrotaria, mais uma vez na carne, a própria morte. ${ }^{50}$ Desse modo, a encarnação de Cristo, cuja finalidade última era o sacrifício soteriológico, permitiria que toda a humanidade se livrasse da corrupção e da morte, como se o Cristo ressuscitado renovasse a humanidade toda em um novo nascimento, que restauraria a integridade do corpo e a eternidade da alma. ${ }^{51}$ Cristo, portanto, seria o novo Adão que refundaria a humanidade.

Assim, sob o enfoque da reflexão teológica do século IV, fica mais evidente a opção de Proba de concentrar seus esforços narrativos na oposição entre a queda do

\footnotetext{
${ }^{46}$ Cf. Symbolum Nicaenum, 12: Et expecto resurrectionem mortuorum, et uitam uenturi saeculi.

${ }^{47}$ Cf. Santo Atanásio. Contra os pagãos; A encarnação do Verbo; Apologia ao Imperador Constâncio; Apologia de sua fuga; Vida e conduta de S. Antão. São Paulo: Paulus, 2002, p. 127.

${ }^{48}$ Cf. Santo Atanásio, op. cit., p. 130; e cf. Liber Sap. 2, 23-24: Quoniam Deus creauit hominem inexterminabilem et ad imaginem suae similitudinis fecit illum/ inuidia autem diaboli mors introiuit in orbem terrarum.

${ }^{49}$ Cf. Santo Atanásio, op. cit., p. 132.

${ }^{50}$ Cf. Santo Atanásio, op. cit., p. 134.

${ }^{51}$ Cf. Santo Atanásio, op. cit., p. 143.

66
} 


\section{nuntius antiquus}

homem, objeto da primeira metade do centão, e a vida salvífica de Cristo, objeto da segunda parte do poema, em reforço à teoria da função educativa do Carmen Sacrum.

\section{Conclusão}

Embora tenha alcançado vasta repercussão na Antiguidade e a Idade Média, a Modernidade, com sua busca incansável pelo ineditismo, relegou a técnica centonista à condição de produção poética menor, como se as estruturas formulares extraídas dos versos dos autores considerados modelares não pudessem ser matéria-prima para produção literária. Por esse motivo, as edições do texto de Proba, tão comuns até a Idade Média, ${ }^{52}$ tornaram-se raras e nenhuma tradução foi ainda empreendida em língua portuguesa. Entretanto, o inevitável diálogo comparatista entre tantos textos - as narrativas bíblicas e evangélica e os poemas virgilianos - não apenas permite a compreensão da formação do corpus literário do cristianismo primitivo a partir dos escombros da Antiguidade, como também demonstra a lógica argumentativa do convencimento apologético exercido no período de transição do paganismo.

\section{Referências}

ARBEA, A. El "Carmen Sacrum" de Faltonia Betitia Proba, la primera poetisa cristiana. Cyberhumanitatis. Santiago: Pontificia Universidad Católica de Chile, n. XI, 1999. (disponível em <http://www2.cyberhumanitatis.uchile.cl/11/arbea.html> acesso em 12 abr. 10).

BÍBLIA. Tradução ecumênica. Edições Loyola, São Paulo, 1994.

DOMINGUEZ, O. P. Historia del Centón griego. Cuadernos de filología clásica. Estudios griegos e indoeuropeos. Madrid: Universidad Complutense, 2009, p. 217-232.

ERMINI, F. Il "Centone di Proba” e la poesia centonaria latina. Roma: Ermanno Loescher \& C, 1909.

MARROU, H.-I. História da educação na Antiguidade. Trad. de Mário Leônidas Casanova São Paulo: EPU, 1973.

MECONI, D. V. The "Christian Cento" and the evangelization of Christian culture. Logos: a journal of catholic thought and culture. St. Paul: University St. Thomas, vol. VII, n. 4, p. 109-132, 2004.

${ }^{52}$ Cf. Ermini, op. cit., p. 142. 
PROBA, Faltonia B. Centones Probae Falconiae de utriusque testamenti hystoriis ex carminibus Virgilii selecti cum annotatione locorum, ex quibus desumpti sunt. Oppenheymium: 1517 (disponível em <http://daten.digitalesammlungen.de/ db/bsb00002244/images > acesso em 12 abr. 10).

PROBA, Faltonia B. Virgilio-Centones ueteris et noui testamenti. Leipzig: 1492 (disponível em <http://daten.digitale-sammlungen.de/ db/0001/bsb00013428/images/> acesso em 12 abr. 10).

SANTO ATANÁSIO. Contra os pagãos; A encarnação do Verbo; Apologia ao Imperador Constâncio; Apologia de sua fuga; Vida e conduta de S. Antão. São Paulo: Paulus, 2002.

SHANZER, D. The anonymous "Carmen contra paganos" and the date and identity of the centonist Proba. Revue des études augustiniennes. Paris, vol. XXXII, p. 232-248, 1986.

SIVAN, H. Ancian women, the "Cento of Proba", and aristocratic conversion in the fourth century. Vigiliae Christianae. Leiden, vol. XLVII, p. 140-157, 1993.

STEVENSON, J. Women Latin poets, language, gender and authority. Oxford: University Press, 2005, p. 65-71. 